\title{
THE EXCRETION OF SPECIFIC FLUORESCENT SUBSTANCES IN THE. URINE IN EXPERIMENTAL NICOTINIC ACID DEFICIENCY 1.2
}

\author{
By VICTOR A. NAJJAR, HAROLD J. STEIN, ${ }^{3}$ L. EMMETT HOLT, JR., \\ AND CAROL V. KABLER \\ From the Departments of Pediatrics and Medicinc, Johns Hopkins University, Baltimore)
}

(Received for publication November 12, 1941)

In a recent publication (1) the authors have described the presence in urine of certain fluorescent substances which were found to vary in a characteristic way in pellagra. One of these substances, designated $F_{1}$, was found in relatively small amounts in normal urine but in larger quantities in pellagra. The second substance, designated $F_{2}$, developed fluorescence only on the addition of alkali. $F_{2}$ was not found in the urine of pellagrins but reappeared after nicotinic acid therapy. The administration of nicotinic acid to normal subjects caused an increased elimination of $F_{2}$. These facts are summarized in Table I, which also gives the characteristics of the fluorescent spectra of the two substances with ultraviolet light. Photographs of the fluorescent spectra are shown in Figure 1.

To explain these phenomena it was suggested that $F_{1}$ was converted into $F_{2}$ through the agency of some nicotinic acid containing enzyme, a deficit of nicotinic acid causing the accumulation of $F_{1}$ which could no longer be converted into $F_{2}$. It was further suggested that the accumulation of

TABLE I

Features of fluorescent substances as observed in human urine

\begin{tabular}{c|cc}
\hline \hline & \multicolumn{1}{|c}{$\mathrm{F}_{1}$} & \multicolumn{1}{c}{$\mathrm{F}_{2}$} \\
\cline { 2 - 3 } & $\begin{array}{l}\text { Little in normal } \\
\text { urine }\end{array}$ & $\begin{array}{c}\text { Much in normal } \\
\text { urine }\end{array}$ \\
\hline $\begin{array}{c}\text { Abundant in pel- } \\
\text { lagra }\end{array}$ & Absent in pellagra \\
\hline $\begin{array}{c}\text { Fluorescence } \\
\text { Range of }\end{array}$ & $\begin{array}{ll}\text { Whitish, violet blue } \\
\text { Maximum emission }\end{array}$ & Greenish blue \\
\hline
\end{tabular}

1 Read before the Society for Pediatric Research, Atlantic City, New Jersey, May 6th, 1941.

2 Aided by grants from Mead Johnson and Company, Evansville, Indiana, and from the Rockefeller Foundation Fluid Research Fund.

${ }^{3}$ Fleischmann Fellow in Medicine.
$F_{1}$ might be related to the photosensitivity of the skin seen in pellagra.

Since natural pellagra is seldom an uncomplicated nicotinic acid deficiency (2), it seemed desirable to study the excretion of these fluorescent substances in animals with a pure nicotinic acid deficiency.

\section{EXPERIMENTAL}

Four dogs were employed in this study. These animals had previously been used for a nicotinic acid deficiency experiment, but had subsequently received treatment with nicotinic acid. There was no reason to believe that their recovery was not complete at the onset of the present study. Throughout the course of the study the animals received unlimited quantities of a black-tongue diet consisting of :
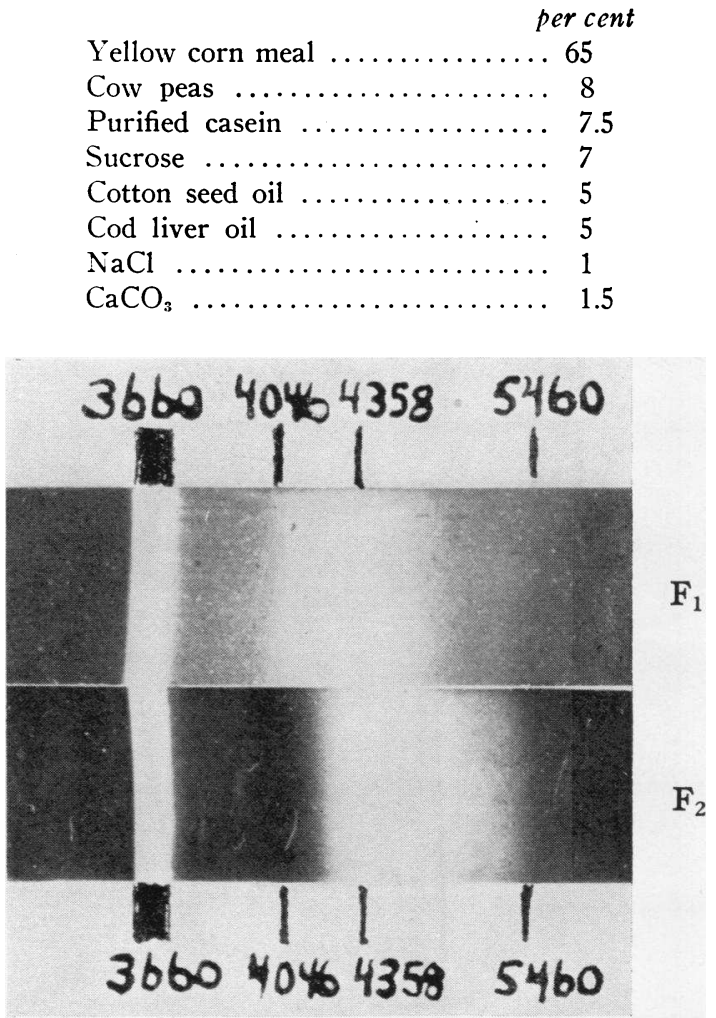

Fig. 1. Pinotograph of the Fluorescent Spectra 
In addition, supplements of thiamin and riboflavin were given to each dog twice a week in doses of $0.175 \mathrm{mgm}$. per kilogram. The dogs were put in metabolism cages every few days in order to obtain 24-hour specimens of urine. The urine was collected in bottles containing glacial acetic acid ( 3 per cent of the anticipated daily volume of urine) and was assayed for $F_{1}$ and $F_{2}$ in quinine units by procedures described elsewhere $(1,3)$.

\section{RESLLTS}

The course of the $F_{1}$ and $F_{2}$ excretion in these animals is shown in Figures 2, 3, 4 and 5. It may be noted that in all but one of the animals the $F_{2}$ excretion at the start of the experiment exceeded that of $F_{1}$. As the experiment continued, $F_{2}$ excretion gradually decreased to zero; this occurred more rapidly in the small dog than in the larger animals. The excretion of $\mathrm{F}_{2}$ remained at the zero level unless nicotinic acid was given. Coincident with the fall of $F_{2}$ in the urine, there was a rise in the excretion of $\mathrm{F}_{1}$, which reached a maximum at or shortly after the time that the $\mathrm{F}_{2}$ output ceased. This maximum $F_{1}$ output was, however, not sustained; as the diet continued, the $F_{1}$ showed a gradual decline to

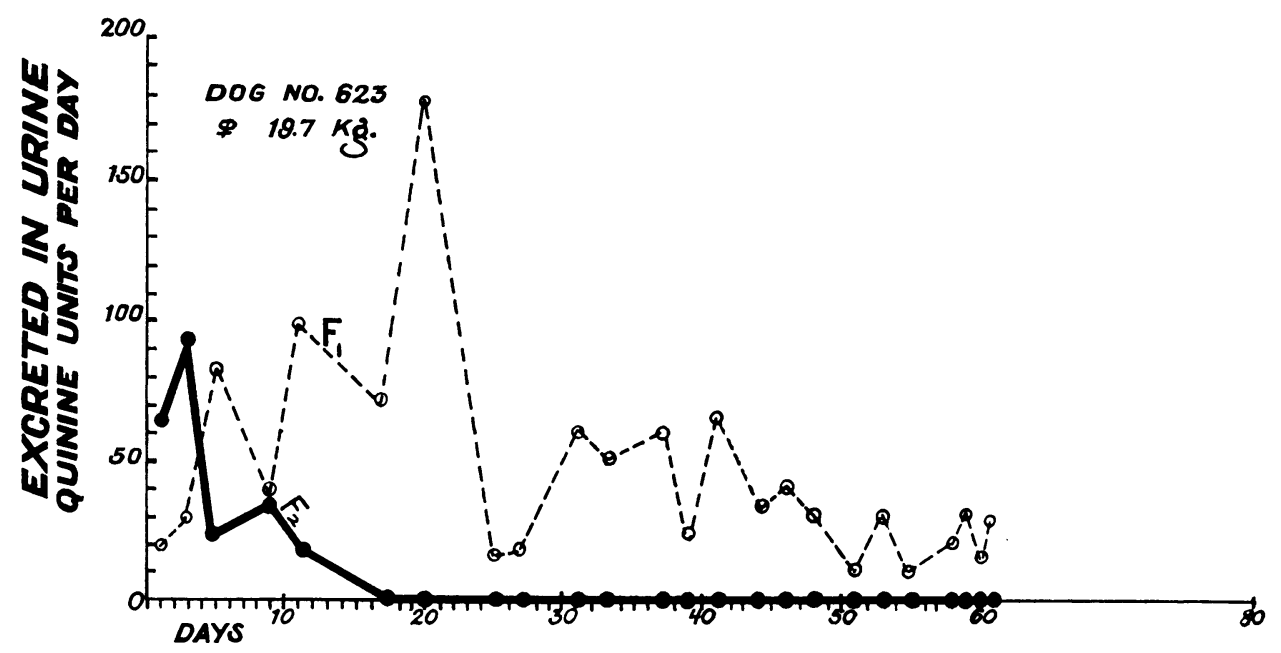

Fig. 2. Excretion of Fluorescent Substances in Experimental Nicotinic Acid DEFICIENCY

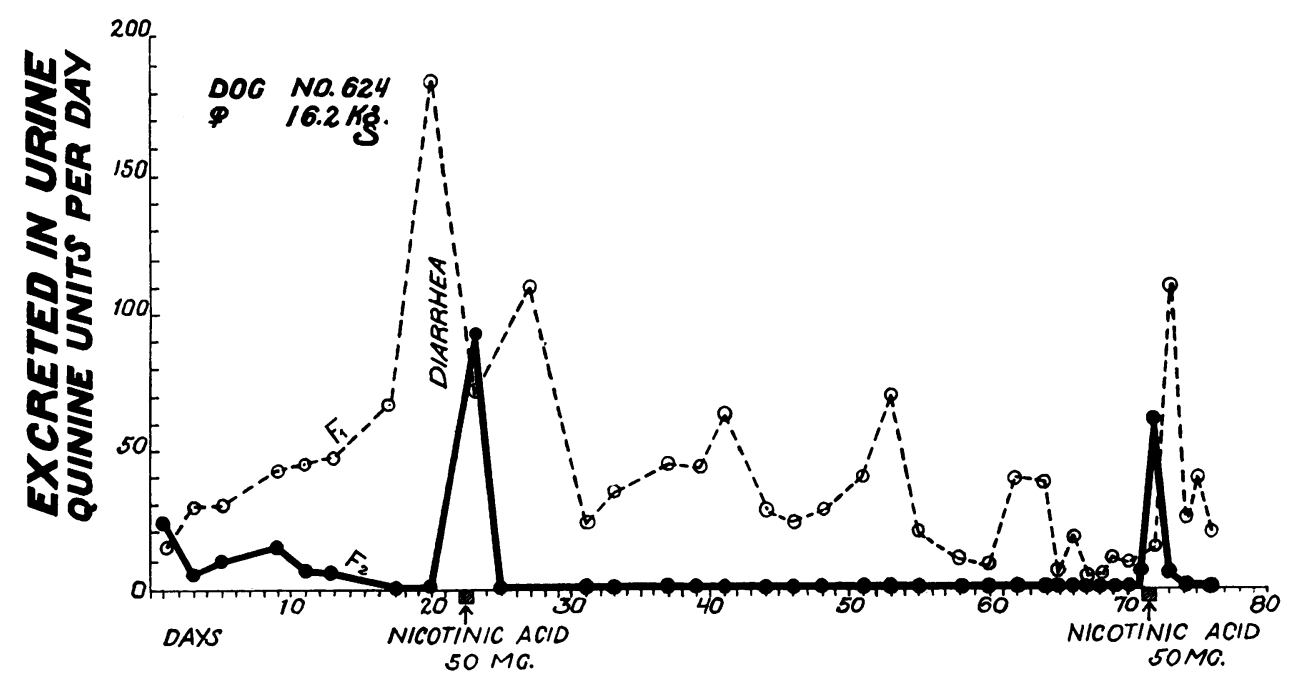

Fig. 3. Excretion of Fiuorescent Substances in Experimentai. Nicotinic Acid Deficiency 


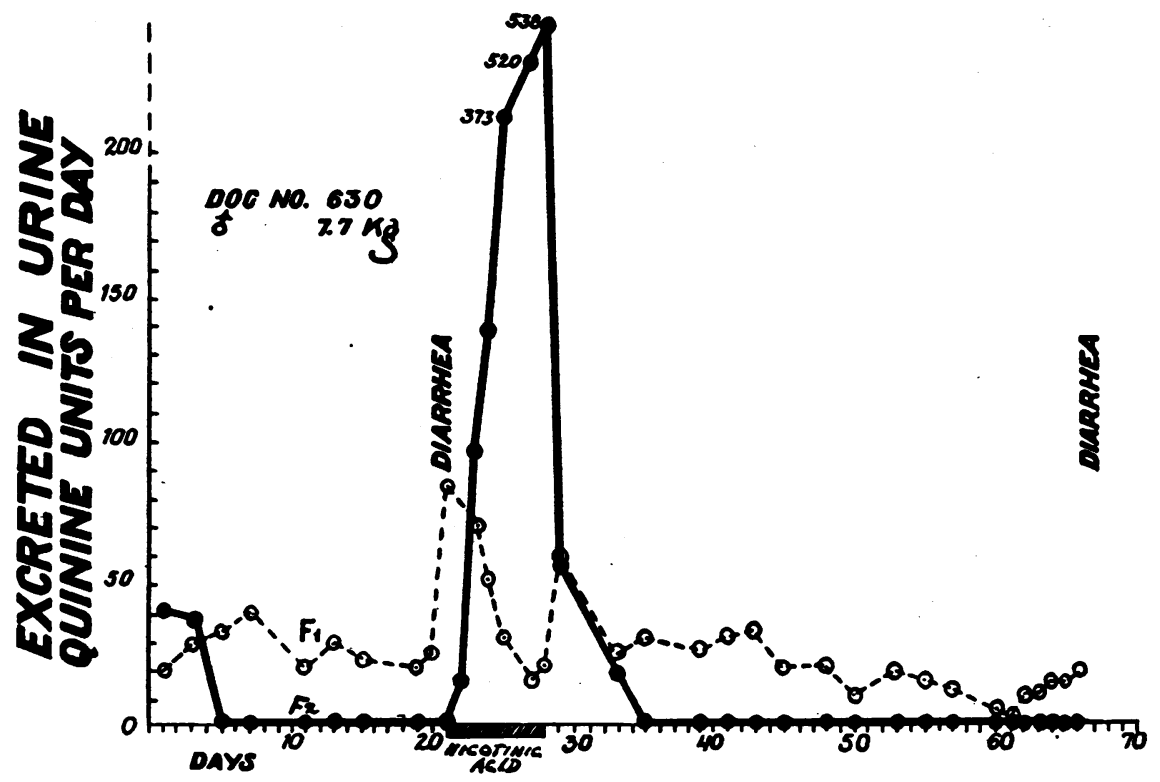

Fig. 4. Excretion of Fluorescent Substances in Experimental Nicotinic Acid Deficiency

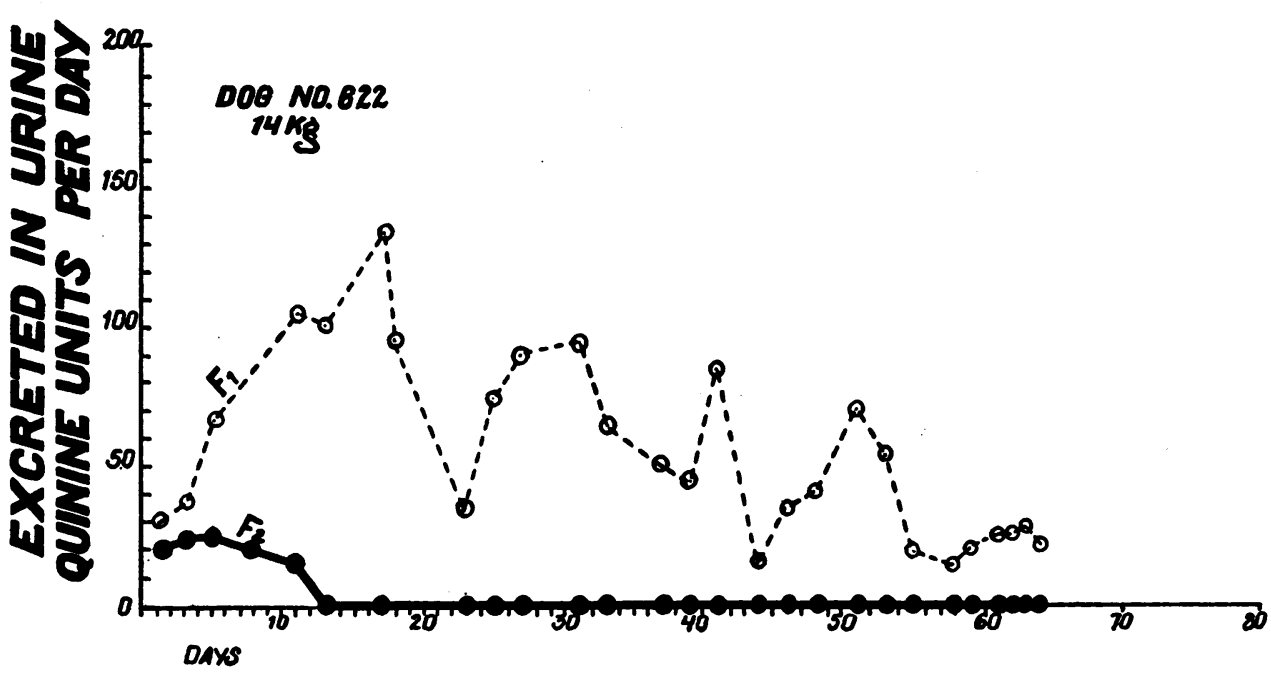

Fig. 5. Excretion of Fluorescent Substances in Experimental Nicotinic Acid Deficiency

values approximating those at the onset of the experiment.

The effect of nicotinic acid therapy is shown in Dogs 624 and 630. The former animal developed diarrhea on the 20th day of the experiment and was subsequently given a single $50 \mathrm{mgm}$. dose of nicotinic acid orally. This medication caused a cessation of the diarrhea, a prompt rise in $F_{2}$ and $a$ diminution in $F_{1}$ excretion. The $F_{2}$ ex- cretion was shortlived, however. In the next specimen it had again disappeared and $F_{1}$ had increased, although the high $F_{1}$ excretion was not sustained. On the 71st day of the experiment a second $50 \mathrm{mgm}$. dose of nicotinic acid was given. This too, was followed by the prompt reappearance of $F_{2}$ in the urine. The $F_{1}$, however, which had by then reached a low level, did not fall as a result of this dose. Indeed, it may be noted that 
it showed no change at all for 24 hours, but following this exhibited a sharp but transitory increase.

The small dog Number 630 showed, in general, a similar response to nicotinic acid. On the 21 st day of the experiment he developed diarrhea. His $F_{1}$ excretion had by that time risen from 20 to 170 units per day, and his $F_{2}$ had fallen to zero. He was then given $50 \mathrm{mgm}$. nicotinic acid a day by mouth for one week. This resulted in a rise of $\mathrm{F}_{2}$ to extraordinarily high levels and in a simultaneous decrease of $F_{1}$. Following the withdrawal of nicotinic acid, the $\mathrm{F}_{2}$ excretion fell to zero in the course of a week, and $F_{1}$, after a temporary rise, continued to decline steadily until the termination of the experiment.

\section{COMMENT}

The observations made on these animals confirm those made on 4 pellagrins studied by us (Table II). The dog experiments, like the studies of patients, demonstrate the absence of $\mathrm{F}_{2}$ excretion and the tendency of $F_{1}$ to rise. Somewhat unexpected, however, was the observation made on the dogs that the rise in $F_{1}$ was not indefinitely sustained. In examining the human data from this point of view, it is worthy of note that the most severe case of all, as judged by history, symptoms and reappearance of $\mathrm{F}_{2}$ in the urine after therapy (Patient E), did not show as high an $F_{1}$ excretion as did another definitely milder case (Patient S). It now seems likely that the stage of high $F_{1}$ excretion had been passed in this severe case, and that the condition was comparable to that observed in our dogs after many weeks on the experimental diet.
Although, in general, a reciprocal relation between $F_{1}$ and $F_{2}$ excretion seems to hold, it is now apparent that this relationship is not a perfect one. The fall in $F_{2}$ on withdrawing nicotinic acid is not always accompanied by an equally prompt and impressive rise in $F_{1}$ (Dog 630). Likewise the administration of nicotinic acid may cause a rise in $F_{2}$ excretion far greater than the fall in $F_{1}$ (Dog 630) or may under other circumstances (Patient $E$ ) cause a reduction in $F_{1}$ without any corresponding rise in $\mathrm{F}_{2}$.

In interpreting these facts, one must bear in mind the possibility that one or both of these substances may be of physiological importance, and that the failure of one to appear quantitatively as the other disappears may be due to a demand made by the body which results in utilization rather than excretion. It is also possible that intermediary non-fluorescent compounds are formed in the conversion of $F_{1}$ to $F_{2}$. Furthermore, one cannot deny the possibility that the reactions causing the disappearance of $F_{1}$ and the appearance of $\mathrm{F}_{2}$ are two independent reactions, both of which are catalyzed by nicotinic acid.

The gradual decrease in $F_{1}$ excretion in the later stages of the deficiency also demands an explanation. In the absence of knowledge of the chemical nature or precursors of this substance, this can hardly be discussed with profit at the present time. It is hoped that studies now in progress will throw some light on the subject.

\section{SUMMARY}

The fluorescent substances $F_{1}$ and $F_{2}$ have been followed in the urine of dogs with experimental

TABLE II

Urinary excretion of $F_{1}$ and $F_{2}$ in pellagrins *

(Expressed in quinine units)

\begin{tabular}{c|c|c|c|c|c}
\hline \hline \multirow{2}{*}{ Subject } & \multirow{2}{*}{ Severity of symptoms } & \multicolumn{2}{|c|}{ Before treatment } & \multicolumn{2}{c}{ After 50 mgm. nicotinic acid by mouth } \\
\cline { 2 - 5 } & & $F_{1}$ & $F_{2}$ & $F_{1}$ & $F_{2}$ \\
\hline W. & Very mild & 12 & 0 & 22 & 18 \\
H. & Moderately severe & 38 & 0 & 26 & 17 \\
S. & Moderately severe & 104 & 0 & 60 & 0 \\
E. & Very severe & 64 & 0 & 40 & $35-50$ \\
Normal control subjects & $10-15$ & $20-35$ & $15-20$ & 0 \\
\hline
\end{tabular}

* Figures represent excretion during a 4-hour period. 
nicotinic acid deficiency. Observations on these animals are in agreement with those made in human pellagra that acute nicotinic acid deficiency is characterized by the disappearance of $F_{2}$ excretion and a rise in $F_{1}$ excretion. As the disease becomes more chronic, the excretion of $F_{1}$ likewise tends to fall. The effect of nicotinic acid in reversing these changes is illustrated.

\section{BIBLIOGRAPHY}

1. Najjar, V. A., and Holt, L. E., Jr., The excretion of specific fluorescent substances in the urine in pellagra. Science, 1941, 93, 20.

2. Sydenstricker, V. P., Clinical manifestations of nicotinic acid and riboflavin deficiency (pellagra). Ann. Int. Med., 1941, 14, 1499.

3. Najjar, V. A., and Wood, R. W., Presence of a hitherto unrecognized nicotinic acid derivative in urine. Proc. Soc. Exper. Biol. and Med., 1940, 44, 386. 